\title{
En nombre del desarrollo, el interés nacional y el bien común: violencia legítima y derecho penal del enemigo en tiempos de antiterrorismo
}

\author{
In the name of development, national interest and common \\ good: legitimate violence and criminal law of the enemy in \\ times of anti-terrorism
}

Mónica Mazariegos Rodas

Universidad Rafael Landívar de Guatemala monicamazariegos@yahoo.com

Cómo citar/Citation: Mazariegos, Mónica. 2020. «En nombre del desarrollo, el interés nacional y el bien común: violencia legítima y derecho penal del enemigo en tiempos de antiterrorismo». Deusto Journal of Human Rights, n. 5: 69-98. doi: http://dx.doi.org/10.18543/djhr.1749

\begin{abstract}
Sumario: Introducción. 1. Continuum de violencia en la formación del Estado. 2. El carácter consustancial de la relación entre violencia «legítima»y extractivismo. 3. El enemigo: criminalización y derecho penal en tiempos de antiterrorismo. 3.1. Definiendo un patrón de criminalización en Guatemala. Reflexiones finales. Referencias
\end{abstract}

Resumen: El artículo analiza la reconceptualización de la noción de enemigo interno en el siglo XXI, así como las reconfiguraciones actuales del uso del derecho penal del enemigo como mecanismo de represión, criminalización y castigo a los movimientos sociales en Guatemala, desarrollando interrogantes y líneas argumentativas que se podrían aplicar a otros países latinoamericanos. El análisis se enmarca en el rol que en la actualidad juega el monopolio de la violencia «legítima» en la razón de Estado, así como en el progresivo posicionamiento de las corporaciones multinacionales y su lex mercatoria frente a la soberanía estatal, no como simples agentes económicos, sino como mecanismos de autoridad política.

Palabras clave: terrorismo, enemigo interno, conflictos socio-ambientales, criminalización, violencia legítima.

Abstract: This article analyses the reconceptualization of the notion of "internal enemy" in the 21st century, as well as the current reconfigurations of the use of criminal law of the enemy as a mechanism of repression, criminalization and punishment of social movements in Guatemala, thus 
raising questions and argumentative lines that could also be applied to other Latin American countries. The analysis relies on the role played by the monopoly of "legitimate" violence in the reason of the State, as well as on the increasing relevance of multinational corporations and their "lex mercatoria" against the sovereignty of the State, not just as mere economic agents, but as forms of political authority.

Keywords: Terrorism, internal enemy, socio-environmental conflicts, criminalization, legitimate violence. 


\section{Introducción}

La reconceptualización del enemigo en la noción del terrorista como amenaza resurge en el mundo occidental tras la caída de las Torres Gemelas en New York, en septiembre de 2001. En Latinoamérica este fenómeno se desenvuelve en el marco de una formulación hemisférica de la seguridad, aplicada a toda actividad que atente contra el Estado y el régimen económico bajo su tutela.

La simbiosis Estado-régimen económico es clave para interpretar, en el contexto latinoamericano de los tiempos "antiterroristas», el uso del derecho penal en la criminalización del disenso ante el modelo de desarrollo. Se experimenta un giro en la identificación del «terrorista», antes asociado a la imagen del "comunista», con dirigentes sociales que se oponen a proyectos extractivos (Svampa 2006 y 2012). Este fenómeno se refuerza con la militarización —estado de excepción- de territorios en disputa, y se ubica en el corazón de conflictos socioambientales que desvelan la intrínseca relación entre derecho, violencia «legítima» e intereses económicos privados.

En este artículo analizo algunas reconfiguraciones del uso del derecho penal del enemigo, como mecanismo de represión, criminalización y castigo a movimientos sociales y defensores/as de derechos humanos ${ }^{1}$. Aunque me refiero a Guatemala, pretendo desarrollar interrogantes y líneas argumentativas que apliquen a otros países latinoamericanos.

Argumento que el ius puniendi se ejerce para criminalizar la defensa de ciertos derechos humanos. Para analizar ese uso del derecho me sostengo en una concepción que no se circunscribe a la perspectiva positivista que lo define como proceso de creación y aplicación de normas coercitivas, sino también lo asume como sistema productor de normas-cotidianidad (cultura) y de estructuras gnoseológicas o de raciocinio (Noguera 2009: 11-38). Sostengo que la criminalización opera, tanto en una dimensión simbólico-discursiva, mediante la estigmatización —creando imaginarios de sanción social que asocian la defensa de ciertos derechos con actos ilegales-, como en una dimensión de judicialización penal, encuadrando estas acciones en conductas tipificadas como delitos. De este fenómeno deriva una

1 «Toda persona tiene derecho, individual o colectivamente, a promover y procurar la protección y realización de los derechos humanos y las libertades fundamentales en los planos nacional e internacional» (Asamblea General ONU, 1999). Así, un defensor/a no se circunscribe a la idea del/la activista o dirigente social, sino puede abarcar a operadores de justicia, periodistas, funcionarios públicos y otros. 
turbadora reconstrucción del enemigo interno, encarnado en quienes impugnan el modelo de desarrollo extractivista.

Interesa a mi análisis el rol que juegan, ante la noción de soberanía, el monopolio de la violencia «legítima» en la razón del Estado contemporáneo, y el progresivo posicionamiento de las corporaciones multinacionales y su lex mercatoria, como mecanismos de autoridad política. Este debate permitirá una aproximación crítica al significado de las nociones de bien común e interés nacional, en nombre de cuya protección intervienen el derecho penal del enemigo y la violencia estatal y priva(tiza)da, demostrando que los intereses del Estado están hoy como nunca vinculados al mercado global.

El artículo reflexiona, finalmente, sobre la ruptura que la violencia "legítima» y el derecho penal del enemigo implican para la visión liberal de los derechos como límites frente al Estado, al evidenciar dos problemas: por un lado, que actores privados detentan poder político y pueden hacerlo arbitrariamente, desde una dialéctica para nada sutil entre lo legal y lo ilegal, que consolida un sistema de privilegios y primacía de la lex mercatoria. Por otro lado, que el ideal de consenso liberal tiene límites en la criminalización y la violencia "legítima», como recursos al uso en los conflictos socioambientales, pues, además de materializar un problemático entendimiento de la soberanía, se imponen como prima ratio frente a concepciones disímiles -incluso antagónicas - sobre asuntos como el desarrollo, el progreso, el interés nacional, el bien común o la felicidad.

\section{Continuum de violencia en la formación del Estado}

La violencia es una constante en el proceso de formación del Estado en Latinoamérica. Desde una etapa pre-estatal, la violencia -y sus discursos de legitimación - fue fundacional a la relación con la alteridad (Mazariegos 2019, 2). En su crítica del «mito de la modernidad», Dussel $(2001,340-358)$ habla de la violencia originaria de la conquista de América, de guerras justas eclipsadas tras un concepto «emancipador» vinculado a la propagación de la religión como vía de salvación. Estas categorías justificaron un sentido cuasiritual del sacrificio del indio colonizado, el esclavo africano, la mujer, la destrucción ecológica de la tierra, etcétera.

La violencia imperial en la historia preestatal tiene un paradigma en las tesis de la guerra justa en el Derecho Indiano y en pensadores como Ginés de Sepúlveda y Francisco de Vitoria. Aunque con importantes matices y contrastes entre sí, ambos justificaron la violencia colonial: 
para Vitoria los indios eran considerados atrasados, pero iguales en humanidad a los españoles, mientras que para Sepúlveda —más influido por la tesis aristotélica de la desigualdad natural- eran considerados atrasados y desiguales. Vitoria defendió una noción de «justos títulos» para declarar la guerra justa, en las leyes para la conquista y reinado de nuevos territorios en América $^{2}$. Por su parte Sepúlveda, en las «Controversias de Valladolid» con Bartolomé de las Casas, defendió como justa la guerra declarada al bárbaro ante su oposición al proceso civilizador ${ }^{3}$.

Las justificaciones de la violencia colonial, la guerra justa y el expolio indígena, fueron desarrolladas también en las teorizaciones sobre gobierno civil de John Locke (2010), que influyeron en el constitucionalismo estadounidense y latinoamericano. El «individualismo posesivo», que concibe las relaciones entre seres humanos como relaciones entre propietarios, y se aplica a la relación entre el individuo y su trabajo, y el individuo y su cuerpo (Macpherson 2005, 13-15, 251-256), adquirió centralidad e impidió "acomodar» una visión indígena que no encajaba en el capitalismo moderno. Al justificar el despojo indígena, por rehusarse al estado civil de los colonizadores, se les despojó de una propiedad que abarcaría desde la tierra hasta su cuerpo. Esta argumentación sustenta una guerra necesaria y justa, para que la conquista pase a la historia como acto legítimo (Hinkelammert 2000, 90-94).

El continuum de estas bases de pensamiento constituye el marco de justificación bajo el cual, en tiempos republicanos, se validaría la expropiación y sobreexplotación indígena y campesina en el siglo XIX. Asimismo, enmarcaría la violencia contrainsurgente de las dictaduras y guerras del siglo xx como justificaciones anticomunistas. Más tarde, en la retórica del desarrollo y el crecimiento económico, legitimaría la violencia del neoliberalismo (Mazariegos 2019, 2) ${ }^{4}$.

2 A diferencia de Sepúlveda objetó el derecho de descubrimiento como justificación de expropiación; la evangelización mediante armas y la corrección de los pecados de los bárbaros (sacrificios humanos) mediante guerra. Rechazó la validez de la entrega voluntaria de soberanía indígena a los españoles y objetó una guerra basada en la condena divina de los bárbaros a la sujeción española. Refutó el «dominio universal del Emperador», la legitimidad de la donación pontificia de las Bulas Alejandrinas de 1493 y los fundamentos del «Acta de Requerimiento» (Vitoria 1946, 47).

3 «Y será siempre justo y conforme al derecho natural que tales gentes (bárbaras) se sometan a... naciones más cultas... Y si rechazan tal imperio se les puede imponer por medio de las armas, y tal guerra será justa» (Sepúlveda 1941, 85-87).

4 Sobre terrorismo de Estado desde los setentas hasta el extractivismo, ver Machado (2010, 59-96). Sobre violencia consustancial al extractivismo ver Acosta (2011, 107-108). 
Cuando a inicios del siglo xx Rosa Luxemburgo $(1913,180)$ ratificó el continuum de violencia de la acumulación originaria en Marx, argumentó que la acumulación primitiva era constante del capitalismo y no solo fase originaria. Afirmó que toda expansión colonial va acompañada de una guerra del capital contra las formas sociales y económicas naturales (originarias, colonizadas), así como de la apropiación violenta de sus medios de producción y sus trabajadores. Ese continuum, en la versión de «acumulación por desposesión» en el siglo XXI, se enfocará en el papel del Estado, tanto por el monopolio de la violencia como por la definición de la legalidad (Harvey 2007, 116-117).

La idea de continuum en esa violencia, permite entender cómo los actuales procesos de despojo pretenden justificarse: por un lado, mediante el uso de un derecho penal que legitima la restricción a los «enemigos» de las garantías del derecho penal liberal y el derecho internacional (Zaffaroni 2006, 16). Volveré sobre este análisis más adelante. Por otro lado, mediante el ejercicio arbitrario del monopolio de la violencia legítima, esa categoría weberiana que refiere al poder estatal de crear orden y seguridad (Weber 2016) y que en este contexto se refiere a la actuación de las fuerzas de seguridad, generalmente mediante estados de excepción. A pesar de que ello expone lo imbuido de violencia que se encuentra el Estado desde sus orígenes, el contenido axiológico de esa legitimidad muy poco se debate, aceptándose tácitamente como parte de los elementos de un consenso sobre su validez democrática. ¿De qué contenidos se dota hoy esa idea de legitimidad? ¿Cómo mutaron esos contenidos en la historia del Estado? ¿Con relación a qué fines y frente a qué sujetos se establecen? ¿Cuáles son los límites de esa violencia para que sea legítima?

Pearce $(2017,3)$ sostiene que la atención de Weber al concepto de «legitimidad» fue limitada. Y que el hecho que el Estado moderno se fundara en la distinción entre la legitimidad de su violencia y la ilegitimidad de la violencia privada, y en la preservación de esta distinción, limita nuestra capacidad de imaginar un Estado que reduce la violencia en virtud de su propia no-violencia. Así, cuestionar la legitimidad de la violencia "pública» (hoy semiprivatizada) es clave en contextos donde se ejerce arbitrariamente, negando no solo la necesidad de discutir lo que entendemos hoy por formas pacíficas y democráticas de convivencia, sino también el daño registrado en una memoria colectiva de pasadas violaciones graves y horrorosas a los derechos humanos.

En el cuestionamiento de la legitimidad es clave el pensamiento de Arendt $(2006,71)$. Ella sostuvo que la violencia puede ser justificable, pero nunca será legítima, y que su justificación pierde plausibilidad cuanto más se aleja en el futuro el fin buscado. La legitimidad, cuando 
es puesta en duda, se basa en una apelación al pasado, mientras que la justificación se refiere a un fin futuro. Siguiendo esta argumentación cabe cuestionar si la militarización se justifica ante la ausencia de realización de ese supuesto fin buscado, sea "desarrollo», «interés nacional», «bien común» u «orden y seguridad». Como sostiene Pearce (2010, 297-298), el proceso de construcción de la violencia en Latinoamérica no se distingue suficientemente del proceso de construcción del Estado de Derecho. La violencia es funcional al modelo económico y aunque se trata como "falla del Estado», podríamos estar ante algo más peligroso: la aparición de formas particulares del Estado para preservar las reglas de las élites, a veces combatiendo y otras concediendo espacio para nuevas élites agresivas que emergen de la acumulación ilegal de riqueza que sostiene este violento (des)orden.

A partir este continuum en la historia de formación del Estado de Derecho en Latinoamérica, cabe abrir preguntas y profundizar en las relaciones y contradicciones entre violencia legítima, criminalización, modelo de desarrollo y democracia liberal.

\section{El carácter consustancial de la relación entre violencia "legítima" y extractivismo}

En el contexto latinoamericano de desigualdad estructural, los gobiernos proponen el extractivismo sostenible como una vía para impulsar progreso, desarrollo y empleo ${ }^{5}$. Este propósito, junto al del cumplimiento de estándares de responsabilidad social, es compartido en el discurso de las empresas extractivas ${ }^{6}$. En las últimas décadas se experimenta una intensificación del extractivismo que, sin embargo, se caracteriza por una relación consustancial con la violencia. Los conflictos socioambientales derivados de megaproyectos llevados a cabo sin consulta a las comunidades afectadas (generalmente indígenas), se gestionan mediante derecho penal y activación de violencia «legítima»: criminalización de dirigentes sociales, declaratoria de estados de excepción o intervención de fuerzas de seguridad en los territorios en disputa.

${ }^{5}$ El informe de transición de gobierno en Guatemala impulsa una política energética sostenible y destaca que el potencial minero del país coincide con las regiones más pobres. (Ministerio de Energía y Minas 2015, 2, 15).

6 Por ejemplo, la Compañía Guatemalteca de Níquel propone como misión «Ser un pilar del desarrollo del país... basado en el compromiso de responsabilidad social y ambiental.» Disponible en: http://www.cgn.com.gt/ 
El extractivismo reconfigura dinámicas de conflictividad en áreas rurales, en un contexto de violencia donde ya no solo actúan propietarios locales sino también corporaciones transnacionales y crimen organizado. Fuerzas públicas de seguridad, estructuras ilegales y clandestinas, y empresas privadas de seguridad participan en violaciones a derechos humanos en el marco de operativos de reinstauración del orden, la gobernabilidad y la seguridad, que, aunque generalmente se justifican en la lucha contra el narcotráfico y el crimen organizado, no ofrecen avances concretos?

Este análisis se complejiza considerando las dificultades de las democracias liberales para zanjar conflictos que plantean antagonismos entre extractivismo y concepciones diversas sobre vivir bien: en las cosmovisiones indígenas no existe una visión lineal del desarrollo, un enfoque antropocéntrico de la naturaleza, ni un propósito de mercantilizarla como "canasta de recursos» ${ }^{8}$. En contraste, la posición de la mayoría de gobiernos y empresas es la de generar desarrollo mediante la explotación de «recursos» naturales. Los discursos del buen vivir conciben al ser humano como uno más de los elementos que interdependientemente conforman la naturaleza. Este planteamiento trasciende los clásicos «desacuerdos entre derechos»: este disenso plantea una ruptura epistémica frente al extractivismo, problematizando la idea de que es siempre posible articular democracia a partir de un consenso racional sobre decisiones políticas (Habermas y Rawls 1998; Rawls 2004; Mouffe 2012). La democracia liberal muestra sus límites al normalizar, o cuando menos tolerar, una violencia que se impone como prima ratio en respuesta a los antagonismos.

En los conflictos socioambientales la vida y la muerte se dirimen en una frontera frágil, porque las luchas sociales no se centran solo en recuperar el control de las decisiones colectivas o reivindicar mejores niveles de vida. Las luchas se centran apenas en un asunto pre-político: mantener cuerpos vivos (Mazariegos 2019, 3). A la enfermedad y muerte por el derrame de tóxicos, o a la sequía y enfermedad por el desvío de ríos, se suman ataques y violencia?

7 Este fenómeno ha sido estudiado por González Briz y Ramiro (2013) en Perú y México, por Hernández Zubizarreta (2009) en Colombia, por Solano (2015) en Guatemala y por Pulido (2012) en México, Colombia y Guatemala.

8 Ver trabajos de Acosta.

9 El jefe de seguridad de la mina San Rafael ordenó un ataque donde resultaron siete heridos: «Maten a esos hijos de la gran... malditos perros que no entienden que la mina genera trabajo». Sus palabras fueron obtenidas en el marco de la investigación penal. Redacción La Hora (2013). 
En 2017 se registraron en Guatemala 493 ataques (13 asesinatos) y 391 en 2018 (26 asesinatos) (UDEFEGUA 2017a) que provienen de actores políticos, crimen organizado, seguridad privada y empresas, o personas contratadas para ello (PDH y OACNUDH 2018, 10). Los estados de sitio eventualmente conllevan desalojos violentos (a veces bajo petición o presión de las empresas ${ }^{10}$ ) y registran abusos sexuales y destrucción de viviendas y cosechas (ADH 2017). El estado de sitio se caracteriza por la suspensión de garantías constitucionales, el uso desproporcionado de fuerza pública, y detenciones arbitrarias, confirmando que el estado de excepción es «la forma legal de aquello que no puede tener forma legal» (Agamben 2005, 24). Los últimos cuatro estados de excepción (entre 2019 y 2020) argumentan la alteración del orden público y la afectación del bien común y la gobernabilidad $^{11}$.

Desde el punto de vista del continuum, no deja de ser revelador que las regiones más afectadas por una guerra que llegó a niveles de genocidio sean las más impactadas hoy con esa violencia que pone en cuestión los acuerdos de paz de 1996 y sus garantías de no repetición. El despojo de la autonomía indígena sobre sus cuerpos y territorios, que golpea con mayor fuerza a las mujeres, es paradigma de esa intersección entre colonialismo, patriarcado y capitalismo que se sostiene con la violencia legítima (Mazariegos 2019,4). De ahí que los feminismos comunitarios y populares propongan recuperar el territoriocuerpo como el "primer territorio» y se desarrollen junto a la lucha de los pueblos para la recuperación y defensa de la naturaleza y el territorio-tierra (Cabnal 2010, 11-25).

La situación es similar en países como México, Honduras o Colombia, que registra un creciente número de asesinatos de líderes indígenas y comunitarios desde 2016, año de la firma del Acuerdo de Paz. En 2018 se registraron 110 asesinatos así como aumento de amenazas, intentos de asesinato y violaciones a los derechos de intimidad y propiedad ${ }^{12}$. La Comisión Interamericana de Derechos Humanos ha condenado estos ataques a nivel regional (CIDH 2017).

10 Previo a la declaración del estado de sitio en San Rafael Las Flores, Santa Rosa, la empresa inició una acción de amparo argumentando que el Estado no estaba velando por su seguridad al permitir que los vecinos se manifestaran (Solano 2015, 15).

11 Ver: Decreto Gubernativo 2-2020 de la Presidencia de la República (Diario de Centroamérica, 2020).

12 Ver el Informe Anual del Alto Comisionado de las Naciones Unidas para los Derechos Humanos del año 2019, párr. 15. 
Aunque la reducción del ejército fue parte de las agendas de transición hacia la democracia y la paz en Latinoamérica, la intervención militar en tareas de seguridad es una constante y no una excepción. En situaciones de posguerra como la guatemalteca o la colombiana se ha denunciado que cuerpos de seguridad privada (trabajando para empresas) o cuerpos de seguridad que formaron parte de estructuras paramilitares han participado en violaciones a los derechos humanos ${ }^{13}$. Este fenómeno de usurpación de competencias del Estado (como la coerción y la regulación social) por actores poderosos que a veces cuentan con su complicidad, es definido por Santos (2005, 374375) como fascismo paraestatal. En este caso hablamos de fascismo contractual (variación del fascismo paraestatal) pues se trata de la eliminación del ámbito del contrato social de aspectos a cargo del Estado que pasan a ser asumidos por agencias paraestatales. Si a ello se suman las ínfimas regalías del extractivismo para el Estado ${ }^{14}$ y su lógica de «enclave», instalándose en los territorios sin integrarse con el resto de la economía y la sociedad, y produciendo un mínimo «valor interno de retorno» (Acosta 2011, 87-95) puede entenderse mejor la oposición al extractivismo.

Si sostenemos el carácter consustancial de la relación entre extractivismo y violencia legítima, y si desde el punto de vista del continuum sostenemos que ésta y su legalidad se encuentran inscritas en la base del capitalismo moderno, podemos sostener también que la soberanía - fundamento del poder coactivo del Estado- hace parte consustancial, y se define y modifica a partir de esta relación. Mbembe (2011, 19-22) nos recuerda que la soberanía reside en la capacidad de decidir quién puede vivir y quién debe morir, más que en el mero recubrimiento de la potencia de la muerte (como poder del soberano), por la administración de los cuerpos y la gestión calculadora de la vida sobre seres vivos (Foucault 1991, 81-95).

Desde esa reflexión me interesa apuntar una cuestión clave: en Latinoamérica están en marcha procesos de corporativización, que refieren a una relación simbiótica entre los Estados y las corporaciones, que permite adecuar políticas y leyes a intereses económicos privados, blindando a las corporaciones a través de la lex mercatoria (Mazariegos 2019, 8). Aunque existen principios de

13 Véase el Informe anual del Alto Comisionado de las Naciones Unidas para los Derechos Humanos sobre las actividades de su oficina en Guatemala, párr. 33.

14 La ley de Minería, aprobada por el Congreso de la República Guatemala en 1997 (Decreto 48-97), no fue consultada con los pueblos indígenas, no reconoce derecho a la consulta y rebaja el porcentaje de regalías del $6 \%$ al $1 \%$ (art. 63) 
ONU sobre responsabilidad social empresarial, «proteger, respetar y remediar» ${ }^{15}$ (Consejo Derechos Humanos, 2008 y 2011) es conocido el debate crítico sobre los límites de su eficacia jurídica, al carecer de efecto vinculante y mecanismos de realización. Asimismo, conocidas son las críticas de la academia y organizaciones sociales al representante especial para la cuestión de los derechos humanos y las empresas, John Ruggie, por un sesgo neoliberal que le restaba imparcialidad y representó apoyo a potencias económicas y empresas (Teitelbaum 2010 y 2011) ${ }^{16}$.

A ello se suma la existencia de tribunales arbitrales internacionales en los tratados de libre comercio como medio — privado- de solución de controversias entre Estados e inversores extranjeros, sustituyendo a tribunales nacionales e internacionales. Estos se impulsaron invocando necesidad de celeridad procesal, descongestionamiento de los tribunales, flexibilidad, neutralidad y confidencialidad en la resolución de conflictos comerciales, argumentando que los tribunales nacionales carecen de estas ventajas.

Sin embargo, también conllevan privilegios procesales asimétricos para las empresas: la elección de la jurisdicción, el no agotar los recursos internos, utilizar el tribunal arbitral como instancia de apelación a sentencias ordinarias y la falta de previsión por la que el Estado pueda demandar al inversor extranjero. Además, desde el punto de vista material se aplican las normas comerciales y no las normas sobre derechos humanos (Hernández Zubizarreta 2009, 239; Guamán 2018).

Este fenómeno expresa un progresivo posicionamiento de las corporaciones sobre el Estado, más que como agentes económicos, como mecanismos de autoridad política que impactan en las diversas manifestaciones de la vida, fagocitan las definiciones de bien común e interés nacional, e influyen en los usos de la violencia estatal. Una crisis del paradigma del contrato social queda expuesta en su

15 Ver «Protect, Respect and Remedy: a Framework for Business and Human Rights. Report of the Special Representative of the Secretary-General on the issue of human rights and transnational corporations and other business enterprises». A/HRC/8/5. Y «Report of the Special Representative of the Secretary General on the issue of human rights and transnational corporations and other business enterprises. Guiding principles on business and human rights: implementing the United Nations «Protect, Respect and Remedy» framework». A/HRC/17/31, del Consejo de Derechos Humanos de Naciones Unidas.

16 Ruggie sostuvo que los derechos solo pueden ser violados por los Estados y no por las personas privadas, salvo ciertos crímenes de guerra y lesa humanidad, y se opuso a recibir denuncias sobre violaciones cometidas por las multinacionales. 
progresivo reemplazo por una contractualización neoliberal integrada por múltiples contratos privados, y evidenciada en el derrumbe de un régimen de valores integrado por el «bien común» y la «voluntad general» (Santos 2005, 367-371).

En realidades como la guatemalteca, la colombiana o la mexicana, donde las redes criminales cuentan como poderes fácticos que interactúan con élites tradicionales, corporaciones multinacionales, funcionarios públicos y partidos políticos, es importante considerar la complejidad que la cooptación del Estado añade a la corporativización. La cooptación se entiende como la acción de agentes legales o ilegales que, mediante prácticas ilegales o legales pero ilegítimas, buscan modificar desde dentro el régimen e influir en las reglas del juego social, con el objetivo de obtener beneficios y asegurar que sus intereses sean validados política y legalmente para obtener legitimidad, aunque no estén regidos por el bien común (Garay y Salcedo-Albarán 2012, 36).

Es preciso reflexionar sobre los efectos que esas redes «políticoeconómicas ilícitas» (CICIG 2015, 19) que oscilan entre lo público y lo privado, lo gubernamental y lo empresarial, lo formal y lo informal, y lo legal y lo ilegal, tienen en los contenidos de una Razón de Estado en la que se sostienen el interés nacional, el bien común, y el desarrollo. Su influencia conlleva mutaciones importantes para los conceptos clásicos de Estado y soberanía. Problematizar esas definiciones requiere preguntarnos cómo esas mutaciones impactan en las actuales configuraciones, representaciones y materializaciones de la violencia legítima, así como en las limitaciones de la propia soberanía como noción progresivamente privatizada, para desarrollar frenos a su propia violencia. ¿Quién exactamente detenta hoy el poder soberano? ¿Qué intereses representa ese poder? ¿En qué medida la soberanía se ha vaciado de su intencionalidad democrática y la ha reemplazado por intereses privados? ¿Cuáles son las consecuencias del vaciamiento de su naturaleza pública?

Cuando Mbembe $(2011,46)$ conceptualiza la soberanía como derecho de matar, enlaza al biopoder con las nociones de estado de excepción y estado de sitio, y examina las trayectorias mediante las que estas y la «relación de enemistad» se convierten en la base normativa del derecho de matar. En estas situaciones el poder invoca la excepción, la urgencia y la noción «ficcionalizada» del enemigo. La violencia «legítima» representa, así, un canal para materializar ese permanente estado de excepción, ese proceso de redefinición del enemigo, ese vaciamiento democrático de la soberanía y su relación de cálculo sobre la vida y la muerte. 
Ese orden de cosas devela una división de la realidad en dos universos: por un lado, el regulatorio-emancipatorio de los derechos en la sociedad dominante, donde habitan la democracia y las subjetividades que importan, y los conflictos se resuelven reguladamente. Por otro, el de apropiación y violencia en territorios marginales, donde el orden y el control del gobierno no se basan en leyes sino en fuerza (Fanon 1975; Santos 2010; Mbembé 2011).

En esa estructura dicotómica las vidas indígenas y campesinas son vidas no llorables (Butler 2006, 181-187) y sus concepciones y valores son desechables. Representan un horizonte frente al que el poder actúa sobre la base de la violencia legitimada por planes de «seguridad nacional» formulados en clave de derecho penal del enemigo. Por eso es normal que sean despojados y desplazados de sus territorios; es normal que se les considere seres sin voz ni criterio propio sobre decisiones que perpetúan la pobreza y les colocan entre la vida y la muerte; es normal que se les criminalice por antagonizar con esa lógica; es normal que se les imponga el sacrificio de sus derechos en pos de un «desarrollo» que les es ajeno porque, ¿a quién le importan esas vidas disociadas del contrato social, del bien común y del interés nacional? (Mazariegos 2019).

\section{El enemigo: criminalización y derecho penal en tiempos de antiterrorismo}

La identificación del enemigo ha mutado con el tiempo. A su tratamiento teórico subyace la estrecha relación entre derecho penal y teoría política. Destacan las influyentes ideas de Carl Schmitt en el derecho penal desde el siglo xx y en la lucha contra el terrorismo en el siglo XXI. Particularmente, la dicotomía amigo-enemigo en la conceptualización de lo político, y otras discusiones como la relación entre las ideas de enemigo esencial, raza y guerra en el contexto del nazismo (Schmitt 2006, 57, 77) o la idea de «enemigo interno» a finales de los sesentas (Schmitt 2005, 22-30).

En el mundo occidental, el enemigo se reconceptualiza en la noción del terrorista como amenaza, luego de la caída de las Torres Gemelas en New York el 11 de septiembre de 2001, identificándose entre otros con los islámicos, o al menos musulmanes (Zaffaroni 2006, 20). Entonces se abre el debate sobre el combate del terrorismo. En la base de la identificación del terrorista y el criminal como enemigos hay un deslizamiento semántico en función de autolegitimación: la confusión 
entre derecho penal y una guerra identificada como «lucha contra el terrorismo» (Ferrajoli 2006, 19-20).

En Latinoamérica, el antecedente inmediato es una historia de dictaduras y guerras en el contexto de Guerra Fría: una noción de enemigo interno, como terrorista, fundada en la Doctrina de Seguridad Nacional ${ }^{17}$ (Feirstein 2009; Epe y Kepfer 2014). Esta noción justificó prácticas contrainsurgentes que implicaban lucha contra las guerrillas y contra toda oposición identificada como comunista. Cuando a estos «enemigos» no se les ejecutaba extrajudicialmente se les desaparecía o encarcelaba, según el contexto (Mazariegos 2019).

Actualmente la articulación del «enemigo» surge de una formulación de la seguridad aplicada a toda actividad que atente contra el Estado y el régimen económico que tutela. La idea de enemigo "terrorista», antes asociado al "comunista», gira en torno a quienes se oponen al extractivismo. La exigencia de derechos indígenas como los territorios o la consulta se convierte entonces en una amenaza "terrorista». Estos derechos, cuyo ejercicio podría prevenir conflictos, son incumplidos por el Estado argumentando generalmente la ausencia de una ley específica, lo cual ha abierto un debate donde se cuestiona la necesidad de regulación. Se argumenta la aplicabilidad directa de los convenios de derechos humanos, el principio de que todo tratado en vigor obliga a los Estados, quienes deben cumplirlo de buena fe (pacta sunt servanda) y que los Estados no pueden incumplir sus obligaciones internacionales invocando su derecho interno ${ }^{18}$.

La identificación que realizan algunos gobiernos entre interés público e interés de empresas transnacionales puede llegar a utilizar el sistema represor del Estado para eliminar la oposición a una multinacional (Pulido 2012). Esa confrontación implica que los estados de «excepción» operen como regla (Zibechi 2014). En ese contexto la criminalización requiere articular una falacia ad terrorem: falacia por generalización precipitada, que consiste en afirmar que alguien es terrorista a partir de mencionar acciones habitualmente delictivas (algaradas callejeras, coacciones, vandalismo...) pero insuficientes, pues el terrorismo es un crimen cualitativamente complejo, donde han de concurrir factores diversos (Marcos 2014). En la retórica antiterrorista

17 La doctrina de seguridad nacional representó la política exterior de EEUU hacia Latinoamérica durante la Guerra Fría. Buscaba que las fuerzas armadas combatieran al «enemigo interno» comunista.

18 Ver Convención de Viena sobre el derecho de los tratados de Naciones Unidas de 1969, en sus artículos 26-27. 
se conjugan, además, estereotipos racistas y anticomunistas: los escenarios de este fenómeno son generalmente territorios indígenas que albergan bienes naturales con potencial extractivo.

En Latinoamérica es preciso apuntar al racismo como dispositivo que habilita la deshumanización del otro, negro o indígena, pero también lo define como enemigo político, como sucedió durante la Guerra Fría (Lemaitre 2011, 62). Resulta emblemático el caso «Norín Catrimán y otros contra Chile», que muestra la relación entre criminalización, extractivismo y racismo: según la Corte Interamericana de Derechos Humanos, los actos de los imputados (atentados incendiarios e incendios, en el marco de un conflicto por la propiedad de tierras que los indígenas consideran ancestrales) fueron calificados como delitos terroristas considerando su origen étnico y su calidad de dirigentes del pueblo Mapuche. La condena no distinguió entre reivindicaciones indígenas legítimas, caracterizadas por formas de protesta, y actos de violencia por grupos minoritarios, calificados como «terroristas». Al no establecerse vínculo de los mapuches con dichos grupos se concluyó que la invocación de su pertenencia étnica constituyó un acto de discriminación mediante el cual se criminalizó su protesta (CIDH 2010).

A partir de este caso es posible encontrar paralelismos regionales en la judicialización de autoridades indígenas o dirigentes comunitarios. Existe un creciente número de casos que exponen el ejercicio del ius puniendi del Estado — su facultad de imponer penas o medidas de seguridad- para criminalizar la defensa de derechos humanos, que demuestran que el derecho penal como última ratio —último recursopara la solución de conflictos hoy es el recurso al uso (Mazariegos $2019,16)^{19}$.

El terrorismo constituye, así, lo que Marcos define como «reservorio simbólico» al que se acude en busca de estrategias retóricas de denigración y estigmatización (Marcos 2014). Y aunque la mayoría de sujetos impactados por este mecanismo son dirigentes sociales, también existen casos de estigmatización o judicialización de jueces y fiscales independientes, abogados y funcionarios diplomáticos o de mecanismos internacionales de protección a los derechos humanos ${ }^{20}$.

19 Sobre criminalización en diversos países de América Latina pueden verse Ospina y Lalander, 2012 y Sánchez, 2017.

20 Este fenómeno es documentado por la prensa en Guatemala, así como por distintos informes de la Procuraduría de los Derechos Humanos. 


\subsection{Definiendo un patrón de criminalización en Guatemala}

A pesar de que Guatemala cuenta con una política criminal que persigue la desjudicialización ${ }^{21}$, la gestión de conflictos socioambientales evidencia una orientación funcionalista del derecho penal, que asocia el temor de la inseguridad ciudadana con la legitimación del poder punitivo. En la práctica se propicia una función represiva, propia de un Estado Policía donde gobierna el arbitrio de la autoridad, más que una social y preventiva, propia de un Estado Democrático de Derecho donde nadie es superior a la ley.

La criminalización en Guatemala consiste en el encuadramiento penal malicioso, ahistórico y descontextualizado de actividades de defensa de ciertos derechos humanos: aquellos que atentan contra el orden económico sustentado en el extractivismo, como la defensa de territorios, recursos naturales o consulta previa, libre e informada a los pueblos indígenas. Esta afirmación se sustenta en la crítica de un «multiculturalismo neoliberal» que surge de la necesidad de convergencia estratégica entre el neoliberalismo y el reconocimiento de unos derechos culturales mínimos (idioma, espiritualidad...), al tiempo que un vigoroso rechazo del resto (como los derechos aludidos), en un mismo proyecto político (Hale 2005; Zizek 1997).

Para analizar el uso represivo del derecho me sostengo en una concepción que no se circunscribe a la perspectiva positivista que lo concibe como proceso de creación y aplicación de normas coercitivas, sino también lo asume como sistema productor de normas-cotidianidad (cultura) y de estructuras gnoseológicas o de raciocinio (Noguera 2009, 11-38). Sostengo que la criminalización opera en una dimensión simbólico-discursiva, mediante la estigmatización —creando imaginarios de sanción social que asocian la defensa de ciertos derechos con actos ilegales-, y en una dimensión de judicialización penal, encuadrando estas acciones en conductas tipificadas como delitos.

La dimensión simbólico-discursiva se expresa mediante la exposición de líderes sociales, autoridades indígenas y defensores de derechos como delincuentes, o al menos como agentes que actúan al margen de la ley, deslegitimando su labor y promoviendo la sanción social (Mazariegos 2019, 6). En esos casos la estigmatización se afinca en la violencia psicológica y el discurso de odio; tiene a medios de comunicación y redes sociales como canales, aunque también

21 Véase la «Política criminal democrática del Estado de Guatemala 2015-2035», del Ministerio Público, del 2015. 
se propaga mediante el rumor a nivel comunitario. En el caso de funcionarios internacionales, la estigmatización opera mediante una narrativa que acusa como «injerencias inapropiadas o indebidas en contra de la soberanía nacional», el acompañamiento, la asistencia o la intervención diplomática en asuntos sobre derechos humanos que se alegan de orden interno 22 .

La segunda dimensión es la judicialización del hecho, a partir de su encuadramiento en un tipo delictivo (Mazariegos 2019,6). Este mecanismo se afinca en el Derecho Penal del Enemigo, rama del derecho propia del Estado policía y originada en el Derecho Romano, donde se definió como hostis al enemigo respecto del cual se podría plantear la guerra y aplicar penas vedadas para los ciudadanos (Zaffaroni 2009, 30-31). El «Derecho Penal del Enemigo» es contrapuesto al "Derecho Penal de Ciudadanos». Jakobs describe el castigo al autor no por la consumación del delito sino por la peligrosidad que representa su conducta o su presumible rechazo al sistema institucional. Afirma que para el poder penal del Estado no todos los ciudadanos son personas, sino que existen «las personas y los enemigos» (Jakobs 1997, 293-324). En el contexto latinoamericano, Zaffaroni $(2006,5)$ describe una rama del derecho que representa tensión porque el tratamiento de seres humanos privados del carácter de personas (enemigos) es propio del Estado absoluto. Se habla de enemigos declarados, no porque ellos declaren su enemistad sino porque el poder los declara como tales.

Aun cuando hablar de derecho penal del enemigo resulta un oxímoron, pues "enemigo» es una idea asociada a la guerra, que es la negación del derecho (Ferrajoli 2006, 16), es importante reconocer que la noción del hostis continúa viva: en Guatemala, la política contrainsurgente de "tierra arrasada» fue la base de operaciones genocidas en los ochentas, a partir de la estrategia de exterminio de comunidades indígenas que pudieran apoyar organizaciones guerrilleras consideradas «enemigo interno». En los noventas, al final de una guerra motivada en gran medida por la injusta distribución de la tierra, el estigma se trasladó a los campesinos: en un contexto de conflictos agrarios sin tribunales agrarios, inició la judicialización por el delito de "usurpación», una figura anteriormente regulada en el derecho civil y tipificada justo después de los Acuerdos de Paz, que fueron la base de nuevos reclamos agrarios (Mazariegos 2019, 7). La

22 El caso más reciente es el cierre de CICIG (2019), aunque ha habido varios casos particularmente desde 2013 con el juicio por genocidio. Ver: Impacto GT (2018). 
usurpación, aplicada a personas que ocupan tierras, vulnera el derecho al debido proceso porque el desalojo se puede ordenar sin audiencia a los afectados y no existen garantías mínimas sobre la certeza del título de propiedad (Grupo de Investigación en Derechos Humanos y Sostenibilidad 2013, 183).

Aunque en Guatemala no hubo un patrón de presos políticos durante la guerra, pues los disidentes eran ejecutados o desaparecidos, en el actual contexto resurge la noción, acuñada por los movimientos sociales, aludiendo a una práctica dictatorial latinoamericana hacia los disidentes del régimen. En una suerte de paralelismo, en tiempos de globalización neoliberal el modelo económico es entendido como «el régimen»: el Estado-nación ha dejado de ser la referencia que explica los dilemas de la soberanía y es sustituido por una economía global operada por corporaciones multinacionales (Mazariegos 2017).

Para leer esta problemática es clave considerar el debate sobre la Justicia Premial, como sistema que «premia» a quienes, habiendo delinquido, colaboran con el esclarecimiento de la verdad judicial, obteniendo una rebaja de la prisión o una sanción alternativa, buscando restringir el uso de la cárcel y evitar procesos largos. Este es un debate abierto en contextos de transición de la guerra a la paz o de dictadura a democracia, así como en contextos de criminalidad organizada. La desjudicialización para delitos de mayor trascendencia se planteó en 2015, con una propuesta de ley formulada por la Comisión Internacional contra la Impunidad en Guatemala - $\mathrm{CICIG}^{23}$. Tras la no renovación del mandato de CICIG por el gobierno en 2019 - luego de acusaciones a personajes de las élites económicas, políticas y militares en casos sobre corrupción y cooptación del Estado- esta propuesta fue modificada en el Congreso, privilegiando lo que la criminología define como «delitos de cuello blanco» (Sutherland, 1983), asociados a casos de corrupción. En contraste, solo entre 2012 y 2017 se registraron 909 actos de criminalización a dirigentes sociales por delitos excluidos de la desjudicialización. Para 2019 había procesos contra comunidades enteras.

Para esbozar el fenómeno, desarrollaré algunos elementos que integran las maneras de ejercer la criminalización:

a. Difamación: La mayoría de casos construyen un discurso mediático que refiere a defensores/as de derechos humanos

23 Mecanismo internacional para la propuesta de reformas institucionales, el apoyo técnico y la investigación de cuerpos ilegales y aparatos clandestinos de seguridad. Colaboró en demostrar la cooptación del Estado por redes criminales. 
como «promotores del conflicto», o «terroristas» (Canal Antigua 2012), asociando la "oposición al desarrollo» al crimen organizado. En el norte de Huehuetenango, una de las zonas de mayor conflictividad en el país, la defensa de los territorios llegó a asociarse al surgimiento de grupos armados (Alianza Nacionalista Guatemalteca 2016).

b. Detención ilegal o arbitraria: Muchos casos inician con una detención ilegal, sin orden de captura librada por juez, que explique los motivos de imputación del delito; o se lleva a cabo por particulares, aun cuando no exista la condición de flagrancia requerida por ley. El Grupo de Trabajo de Naciones Unidas sobre detenciones arbitrarias ha emitido dos opiniones consultivas sobre Guatemala: la primera sobre nueve personas detenidas en una manifestación por el asesinato de una persona en Barillas, Huehuetenango, supuestamente a manos de un agente de seguridad de la hidroeléctrica. La segunda sobre tres personas del Comité de Desarrollo Campesino - CODECA-, detenidas sin autorización. Se concluyó que las detenciones fueron arbitrarias y se recomendó al Estado, en el primer caso devolverles la libertad y, en ambos casos, indemnizarlos y repararlos por los daños ${ }^{24}$.

c. Derecho penal como prima (o única) ratio: Se viola el principio de intervención mínima, según el cual el derecho penal debería ser la última ratio, el último recurso, a falta de otros menos lesivos como el derecho civil, el derecho público o medios extrajurídicos. Este principio indica que debería haber subsidiariedad dentro de las propias sanciones, no imponiendo las graves si basta con otras (Medina 2007, 91). La ley penal se aplica como primer y a veces único recurso, mediante órdenes de captura generalmente acompañadas de allanamientos ${ }^{25}$. El sistema judicial se acciona muchas veces por iniciativa de las empresas o personas individuales que actúan como querellantes adhesivas $^{26}$. La imputación se hace por delitos contenidos en el Código Penal (terrorismo, detención ilegal, asociación ilícita,

24 Ver «Opinión No. 46/2012 del Grupo de Trabajo sobre la Detención Arbitraria» A/HRC/WGAD/2012/46 y "Opinión No. 19/2016 del Grupo de Trabajo sobre la Detención Arbitraria». A/HRC/WGAD/2016, ambos documentos del Consejo de Derechos Humanos de Naciones Unidas.

25 Ver: casos de San Juan Sacatepéquez, Barillas, San Marcos y Santa Rosa y Jalapa (Organizaciones de Derechos Humanos de Guatemala 2013).

26 Hidro Santa Cruz en Barillas, Huehuetenango, accionó contra 9 personas. 
secuestro o usurpación) y en la Ley contra la Delincuencia Organizada (conspiración y asociación ilícita). Aunque se emiten muchas órdenes de captura, pocas han logrado una sentencia condenatoria al ser revocadas durante el proceso por falta de pruebas o por pruebas falsas ${ }^{27}$.

d. Descontextualización y desproporción de las penas. Independientemente del contexto, desde 2014 las imputaciones comienzan a encuadrarse reiteradamente en el tipo penal del plagio o secuestro junto a otros delitos. El plagio o secuestro conlleva pena de muerte y, por tanto, no es susceptible de medidas sustitutivas, por lo que implica el encarcelamiento durante el proceso ${ }^{28}$. Previo a la firma de los Acuerdos de Paz se reformó este delito y el de usurpación, que hoy comparten lo que la doctrina penal denomina tipo penal injusto, que se configura cuando su caracterización es tan amplia que permite que muchas acciones encajen en ella, permitiendo incerteza jurídica para dirimir la acción que realmente transgrede los bienes jurídicos tutelados (Organizaciones de Derechos Humanos de Guatemala 2013) ${ }^{29}$. Antes de su aplicación reiterada se aplicaban otras figuras como el terrorismo; muchas de ellas tenían medidas sustitutivas. Encarcelar a una persona resulta efectivo en términos de desmovilización, porque el encierro desvía la energía social: los presos se vuelven el centro de la lucha y el movimiento se vuelca a cuidarlos, a su defensa legal.

e. Prisión como objetivo. Cuando se aplica otros tipos penales suele generarse desproporción entre culpabilidad y pena. Esta práctica se manifiesta principalmente en una interpretación restringida de las causas de exculpación penal, pues a pesar de que los procesos tienen cargos susceptibles de

27 En San Rafael las Flores más de cien casos han sido desestimados (Solano 2015, 12-13).

28 Artículos 201 del código Penal y 264 del Código Procesal Penal.

29 La formulación del plagio o secuestro da lugar a interpretaciones subjetivas y posibles errores de encuadramiento: "A los autores materiales o intelectuales del delito de plagio o secuestro de una o más personas con el propósito de lograr rescate, canje de personas o la toma de cualquier decisión contraria a la voluntad del secuestrado o con cualquier otro propósito similar o igual...». Esta formulación ha propiciado interpretaciones arbitrarias. Por ejemplo, en momentos en que los agentes de Estado y las comunidades han llegado a tensiones, los líderes son procesados por secuestro tras la simple afirmación de los agentes de que fue variada su voluntad. (CUC, et al., 2013: numerales 63-64, 19 y 67). 
medida sustitutiva, en muchos casos se mantiene la prisión (Organizaciones de Derechos Humanos de Guatemala 2013). Aunque se trate de personas sin antecedentes penales, para mantenerles presos se invoca el argumento de peligro de fuga, atribuido a su peligrosidad. El problema de esta lógica es que, si el imputado es enemigo, el juez se convierte a su vez en "enemigo del reo» y pierde imparcialidad (Ferrajoli 2006, 23). Todo ello cumple con una característica del poder punitivo latinoamericano en su aspecto prisionizante, y es que aproximadamente tres cuartas partes de los presos están sometidos a medidas de contención; son procesados no condenados. Dicho más claramente: casi todo el poder punitivo latinoamericano se ejerce en forma de medidas, o sea que se ha convertido en privación de libertad sin sentencia firme y por presunción de peligrosidad. A ello debe sumarse la resistencia de los tribunales a absolver a las personas en prisión preventiva (Zaffaroni 2006, 25). Esta práctica representa una transgresión a los principios de la política criminal actual y a los principios de ONU para el tratamiento de los reclusos, que establecen que se tratará de abolir o restringir el uso del aislamiento en celda de castigo como sanción disciplinaria y se alentará su abolición o restricción ${ }^{30}$.

f. Litigio malicioso. Los casos se caracterizan por interposición de recursos frívolos e improcedentes, ligereza de las acusaciones y ausencia de conexión entre hechos, derecho y pruebas en la imputación de cargos. Esto no solo ralentiza los procesos, alargando el encarcelamiento y contradiciendo el principio de economía procesal, sino aumenta la carga de trabajo en los tribunales e implica altos costos. Cuanto más trámite se da a recursos frívolos para alargar los procesos, más vulneraciones puede haber al debido proceso.

g. Asimetrías en la persecución penal. El Ministerio Público inicia persecución de oficio a defensores/as de derechos humanos pero no hacia la criminalidad corporativa y del Estado, como contaminación, desvío ilegal de ríos o autorización de actividades contaminantes ${ }^{31}$. Al hablar de conflictividad se alude a medidas de hecho como la quema de maquinaria, delitos contra la propiedad o detenciones ilegales, sin analizar

30 Véanse los «Principios básicos para el tratamiento de los reclusos» de la Asamblea General de ONU 1990. Resolución 45/111.

31 Artículos 347 «a»-347 «c», del Código Penal guatemalteco. Decreto 17-73. 
ilegalidades previas asociadas a la falta de «autorización debida» a concesiones extractivas que han incumplido requisitos legales como la consulta previa a las comunidades afectadas, o los estudios de impacto ambiental ${ }^{32}$.

h. Violencia, zozobra y castigo ejemplar. Hay acciones que crean intranquilidad y zozobra: declaraciones públicas de representantes de empresas o funcionarios, sobre órdenes de detención contra dirigentes sociales, amenazas de muerte (CALAS 2016, 14), intimidación, atentados y asesinatos cometidos por desconocidos o supuestamente por personal de seguridad privada de las empresas ${ }^{33}$. La creación de grupos de choque en el ámbito local, financiados y apoyados por las empresas, la mayoría ligados al personal de seguridad que emplea a exmilitares, y la remilitarización de los territorios son factores que agudizan la conflictividad (Organizaciones de Derechos Humanos de Guatemala 2013, 19).

La judicialización cumple el rol de "castigo ejemplar» al someter a una persona a un proceso como forma de aleccionamiento que tiene intenciones y efectos de neutralización en el resto del movimiento social. Es común que la mayoría de dirigentes se consideren a sí mismos potenciales presos políticos.

\section{Reflexiones finales}

Hacia la conclusión propongo reflexionar sobre la impronta "antiterrorista» de nuestros tiempos y sobre las consecuencias de la asociación que propone entre el derecho y la racionalidad de la guerra. En el difícil contexto de conflictos socioambientales en Guatemala y América Latina, esta se traduce en legitimación de la violencia como regla y en uso malicioso y represivo del derecho penal.

Este fenómeno implica una inversión ideológica del rol que el ius puniendi debería tener en sociedades que aún transitan hacia la democracia y la paz, pues revive la raigambre de castigo al enemigo en el corazón del derecho penal, dando cuenta del continuum de la violencia como elemento fundacional del Estado, así como de la

32 Art. 346 del Código Penal.

33 Andrés Francisco Miguel, fue asesinado durante un estado de sitio en Barillas, Huehuetenango, donde se vinculó por homicidio a dos guardias de Ecoener-Hidralia (Hernández 2013). 
pervivencia de una noción de «enemigo» con una fuerte impronta colonial: los «indios» —enemigos salvajes y bárbaros en los siglos XVI a $\mathrm{XIX}$, $\mathrm{y}$ enemigos comunistas en el $\mathrm{XX}$ - son los enemigos terroristas del siglo XXI.

La complejidad crece si consideramos, además de la codificación racista en la identificación del enemigo, los procesos de corporativización y cooptación del Estado, que dan cuenta de una simbiosis entre poderes públicos y privados reflejada en la progresiva sustitución de ideales como el bien común y el interés nacional, por intereses económicos privados que dotan de sentido al poder soberano y su monopolio legítimo de la violencia.

Respuestas iniciales parecieran hallarse apenas en la vuelta a ideas básicas: el derecho como abanico de garantías democráticas debería proteger el principio de legalidad. La legalidad penal se funda en la verificación de la verdad procesal mediante la relación contextualizada entre acusación, derecho y pruebas, y no en una inquisición arbitraria sobre enemigos identificados a priori. El derecho debe sancionar las transgresiones a partir de acciones cometidas y no a partir de quiénes son sus autores o de la supuesta amenaza o peligrosidad que representan. Si se respeta el derecho a la igualdad, la legalidad penal no puede basarse en la persecución de autores, sino de acciones.

Sin embargo, en tiempos «democráticos» el derecho brinda una impostura legal a la represión, desligándose del principio liberal que lo llama, desde los derechos humanos, a establecer límites al poder, sea público o privado. Hay una continuidad del pasado hacia el presente en el uso del derecho como mecanismo de represión, neutralización y silencio hacia las personas y los movimientos sociales. El Derecho Penal del Enemigo en defensa de intereses económicos privados implica judicialización de las luchas sociales que conlleva cárcel y violación de garantías procesales, sustituyendo en democracia la intervención mínima de la coacción y la potestad punitiva del Estado. Asimismo, la violencia «legítima» del poder soberano es regla y no excepción en el abordaje de conflictos de naturaleza estructural.

El carácter consustancial e histórico de la relación entre extractivismo y violencia, así como la inscripción de su legalidad en la base del capitalismo moderno nos explica que la soberanía - fundamento del poder coactivo del Estado- haga parte de esta relación, y se defina y modifique a partir de ella. Asimismo, que sea difícil contrarrestar la inercia de la violencia estatal, cuando la soberanía protege intereses económicos privados como contenidos solapados de una Razón de Estado que invoca, como axiomas, el interés "nacional» y el bien «común», cuando interviene coactiva y punitivamente. 
A estas reflexiones subyace un antagonismo difícil de resolver desde el pensamiento liberal, porque trasciende los clásicos «desacuerdos entre derechos»: defender concepciones distintas de relación entre los seres humanos y la naturaleza nos aproxima a una noción de bienes comunes que no se explica desde «el» bien común o «el» interés nacional, formulados en términos liberales-representativos. Las discrepancias frente al modelo de desarrollo plantean una ruptura de orden epistémico frente al extractivismo, problematizando la idea de que es siempre posible articular democracia a partir de un consenso racional sobre decisiones políticas. Así las cosas, ¿cuál es el lugar que tienen y cómo se articulan el disenso y los antagonismos en las democracias contemporáneas? Si la naturaleza también es tutelada por leyes penales, ¿cómo justificar el contraste entre la celeridad procesal para capturar y encarcelar a líderes sociales, frente a la ausencia de persecución de crímenes corporativos como la contaminación, la obtención de autorizaciones de forma indebida, o el desvío ilegal de los ríos?

Ante luchas socioambientales que incorporan un clamor muy básico: el de mantener cuerpos vivos, ilesos, sanos, en contextos precarios, es imposible dejar de preguntarse, ¿cómo se justifica la lógica premial de la justicia, como principio desjudicializador, para delincuentes confesos «de cuello blanco» en casos sobre corrupción, mientras la imposición de la prisión preventiva es la regla para dirigentes sociales sin antecedentes penales, cuya culpabilidad no ha sido demostrada? ¿Cómo se explica el incumplimiento del derecho a la consulta previa, libre e informada de los pueblos indígenas y qué argumentos pueden justificar la negación de ese derecho, la impunidad de las industrias extractivas y la militarización de territorios en resistencia? ¿Cómo se explica la convivencia de debates democratizadores de justicia premial que buscan reducir el uso de la cárcel para ciertos delitos, con la permanente amenaza de mecanismos neofascistas de uso del derecho, como la remilitarización mediante Estados de Sitio?

La remilitarización y la dialéctica legal-ilegal en la que se mueven las élites y sus redes para mantener el control social, normalizan el uso de la violencia «legítima» como indicador del continuum del fascismo estatal (y paraestatal). En contextos transicionales, esta dinámica revierte la promesa del «nunca más» y las garantías de no repetición del pasado, y mantiene viva la memoria de represión en la población, inhibiendo el ejercicio de ciudadanía y debilitando la organización social y las prácticas ancestrales, así como sus posibilidades de articulación entre el campo y la ciudad. ¿Existe, en este contexto, alguna violencia que pueda llamarse «legítima»? y en ese caso, ¿qué 
factores determinan esa condición? ¿La no-repetición del pasado podría constituir un canon de legitimidad?

Problematizando la violencia como gramática contemporánea del Estado de Derecho, en contextos de corporativización y cooptación, cabe preguntarse: ¿existe desde el Estado la posibilidad de re-articular nociones de bien(es) común(es) e interés colectivo, llámese nacional o plurinacional (siguiendo las gramáticas fundacionales y refundacionales contemporáneas) que deslegitimen los intereses particulares que normalizan la violencia y las concepciones del enemigo que dotan de contenidos a su ius puniendi? Cabe preguntar si tras una historia de múltiples violencias y lazos rotos, tras estructuras económicas desiguales e injustas y tras conformaciones culturales heterogéneas, es posible que existan conceptos graníticos y unitarios: algo común que encaje en la calidad de «bien» y algo nacional que encaje en la categoría de «interés», o si ha llegado el tiempo de reconceptualizar estas categorías atendiendo a nuestra realidad e historia.

En todo caso, es ineludible impugnar la idea de que es necesario sacrificar algo bueno (derechos) en aras de algo mejor (desarrollo, bien «común», interés «nacional»), y cuestionar las asimetrías del modelo de desarrollo, desde el punto de vista de los beneficios que produce a unos contra los sacrificios que impone a otros. Rescatar la potencia de los derechos humanos para limitar al poder.

Finalmente, cabe reflexionar acerca del rol contrahegemónico que el derecho debería tener en esta tarea crucial y en el tipo de Estado de derecho que construimos al normalizar, no solo la violencia y la construcción del «enemigo» en tiempos de exigencia democrática, sino la imposición del sacrificio de derechos, en pos de cierto entendimiento del desarrollo, el bien común y el interés nacional, precisamente a quienes, además de tener menor capacidad de sacrificio, se encuentran aún a la espera de reparación histórica.

\section{Referencias}

Acosta, Alberto. 2011. "Extractivismo y neoextractivismo: dos caras de una misma maldición». En Más allá del desarrollo, editado por Grupo de

Trabajo Alternativas al Desarrollo, 83-120. Quito: Abya Yala.

Agamben, Giorgio. 2005. Estado de Excepción. Homo Sacer II, I. Buenos Aires: Adriana Hidalgo Editora.

Alianza Nacionalista Guatemalteca. 2016. "Terrorista fuerzas armadas campesinas». Consultado 30 julio 2018. https://www.youtube.com/ watch? $=$ WBqggljyPME

Arendt, Hannah. 2006. Sobre la Violencia. Madrid: Alianza. 
Asamblea departamental de pueblos de Huehuetenango (ADH) et al. 2017. «Guatemala: Derechos humanos e hidroeléctricas. Compendio de información que presentan organizaciones y comunidades a la CIDH». Consultado 18 julio 2019. https://www.business-humanrights.org/sites/ default/files/documents/19_03_17_Guate_Hidro.pdf

Asamblea General de ONU. 1999. "Declaración sobre el derecho y el deber de los individuos, los grupos y las instituciones de promover y proteger los derechos humanos y libertades fundamentales universalmente reconocidos». Consultado 9 junio 2018. http://www.ohchr.org/Documents/ Issues/Defenders/Declaration/declaration_sp.pdf.

Butler, Judith. 2006. Vida precaria. El poder del duelo y la violencia. Buenos Aires: Paidós.

Cabnal, Lorena. 2010. Feminismos diversos: el feminismo comunitario. Madrid: ACSUR Las Segovias.

Canal Antigua. 2012. «Reportaje Especial con Sylvia Gereda. Conocerá el lado oculto de los fondos que Suecia invierte, sus donaciones para financiar terroristas en Guatemala». Consultado 15 julio 2018. http://www.youtube. $\mathrm{com} /$ watch?v=_i_elSm8IfI

Centro de acción legal, ambiental y social (CALAS). 2016. «Criminalización de defensores/as de derechos humanos ambientales que resisten a la imposición de proyectos mineros. Dos estudios de caso». Guatemala, febrero.

Comisión Interamericana de Derechos Humanos (CIDH). 2017. «CIDH condena asesinatos a defensoras/es de derechos humanos en la región». Consultado 19 julio 2018. http://www.oas.org/es/cidh/prensa/comunicados/2017/011.asp

Comisión Interamericana de Derechos Humanos (CIDH). 2010. «Informe de Fondo No. 176/10, Casos 12.576, 12.611 y 12.612. Segundo Aniceto Norín Catrimán, Juan Patricio Marileo Saravia, Víctor Ancalaf Llaupe y otros contra Chile». Consultado 28 julio 2018. www.oas.org/es/cidh/decisiones/ corte/12.576FondoEsp.doc

Comisión Internacional contra la Impunidad en Guatemala (CICIG). 2015. «Financiamiento de la política en Guatemala». Consultado 4 marzo 2019. http://www.cicig.org/uploads/documents/2015/informe_financiamiento_ politicagt.pdf

Diario de Centroamérica. 2020. «Decreto Gubernativo 2-2020 de la Presidencia de la República». Guatemala, 17 de enero. Consultado 8 enero 2020. https://www.minfin.gob.gt/images/downloads/leyes_acuerdos/DECRETO12020_220120.pdf

Dussel, Enrique. 2001. Hacia una Filosofía Política Crítica. Bilbao: Desclée de Brouwer

Epe, Mathias y Rodolfo Kepfer. 2014. El enemigo interno en Guatemala. Contrainsurgencia y su herencia en la configuración de nuevos conflictos. Guatemala: Magna Terra.

Fanon, Frantz. 1975. Pele negra, mascaras brancas. Porto: Paisagem.

Feirstein, Daniel. 2009. Terrorismo de Estado y genocidio en América latina. Buenos Aires: Prometeo Libros. 
Ferrajoli, Luigi. 2006. «El derecho penal del enemigo y la disolución del derecho penal». Nuevo Foro Penal 69: 13-31.

Foucault, Michel. 1991. Historia de la Sexualidad I. La voluntad de saber. Madrid: Siglo XXI.

Garay, Luis Jorge y Eduardo Salcedo-Albarán. 2012. Narcotráfico, corrupción y Estados. Cómo las redes ilícitas han reconfigurado las instituciones en Colombia, Guatemala y México. Bogotá: Random House Mondadori.

González Briz, Erika y Pedro Ramiro. 2013. «Resistir a las transnacionales: los movimientos sociales frente a las grandes corporaciones en Europa y América Latina». En Empresas transnacionales en América Latina. Editado por Juan Hernández Zubizarreta, 234-259. Bilbao: Hegoa.

Grupo de investigación en derechos humanos y sostenibilidad. 2013. Informe de situación de los derechos humanos en Guatemala 2011-2012. Terrassa: Cátedra UNESCO en Sostenibilitat, Universitat Politecnica de Catalunya.

Guamán, Adoración. 2018. «Derechos Humanos y empresas transnacionales, la necesidad de un instrumento internacional jurídicamente vinculante». Revista de Derecho Social 81: 197-218.

Habermas, Jürgen y John Rawls. 1998. Debate sobre el liberalismo político. Barcelona: Paidós.

Hale, Charles. 2005. «Neoliberal multiculturalism». POLAR: Political and legal anthropology review 28, n. 1: 10-19.

Harvey, David. 2007. El nuevo imperialismo. Madrid: Akal.

Hernández, Osvaldo. 2013. "La muerte inconclusa de Andrés Pedro Miguel». Plaza Pública. Consultado 2 agosto 2018. https://www.plazapublica.com. $\mathrm{gt} /$ content/la-muerte-inconclusa-de-andres-pedro-miguel

Hernández Zubizarreta, Juan. 2009. Las empresas transnacionales frente a los derechos humanos: historia de una asimetría normativa. Bilbao: Hegoa.

Hinkelammert, Franz. 2000. "La inversión de los derechos humanos: el caso de John Locke». En El Vuelo de Anteo, Derechos Humanos y Crítica de la Razón Liberal, Editado por Joaquín Herrera, 79-113. Bilbao: Desclée de Brower.

Impacto GT. 2018. Jimmy Morales rechaza renovar mandato de misión anticorrupción de la ONU, 31 de agosto. Consultado 18 de noviembre 2019. https://impacto.gt/guatemala-rechaza-renovar-mandato-de-misionanticorrupcion-de-onu/.

Jakobs, Günther. 1997. «Criminalización en el estadio previo a la lesión de un bien jurídico». En Estudios de Derecho Penal, 293-324. Madrid: UAM, Civitas.

Lemaitre, Julieta. 2011. «¿Constitución o barbarie? Cómo repensar el derecho en las zonas «sin ley»». En El derecho en América Latina, coordinado por César Rodríguez Garavito, 47-68. Buenos Aires: Siglo XXI.

Locke, John. 2010. Segundo Tratado sobre Gobierno Civil. Madrid: Tecnos.

Luxemburgo, Rosa de. 1913. La acumulación del capital. Barcelona: Internacionals Sedov.

Machado, Horacio. 2010. «'El agua vale más que el oro'. Grito de resistencia decolonial contra los nuevos dispositivos expropiatorios». En Ecología política de la Minería en América Latina compilado por Gian Carlo Delgado, 59-96. México, D.F.: UNAM. 
Macpherson, Brough. 2005. La teoría política del individualismo posesivo. De Hobbes a Locke. Madrid: Trotta.

Marcos, Gonzalo. 2014. «Falacia ad terrorem en el discurso público sobre terrorismo». Ciencia y Sociedad 39, n. 2: 245-268

Mazariegos, Mónica. 2019. "Claves de la(s) violencia(s) en las rutas del extractivismo neoliberal en América Latina». En Conflicto y democracia. Espacios ideológicos y culturales. Coordinado por Ángela Sierra. Tenerife: Universidad La Laguna.

Mazariegos, Mónica. 2017. "Seguridad y Violencia». Revista Plaza Pública. Consultado 21 de noviembre 2019: https://www. plazapublica.com.gt/ content/historia-deuna-relacion-violenta

Mbembe, Achile. 2011. Necropolitica. Madrid: Melusina.

Medina, Arnel. 2007. "Los principios limitativos del ius puniendi y las alternativas a las penas privativas de libertad». Ius, Revista del Instituto de Ciencias Jurídicas de Puebla 19: 87-116.

Ministerio de Energía y Minas, Guatemala. 2015. «Condición sectorial 2015». Consultado 20 noviembre 2019: http://www.mem.gob.gt/wp-content/ uploads/2016/01/CONDICI\%C3\%93N-SECTORIAL-2015.pdf

Mouffe, Chantal. 2012. La paradoja democrática. El peligro del consenso en la política contemporánea. Barcelona: Gedisa.

Noguera, Albert. 2009. «Reformulando la sociología jurídica: transformaciones del derecho en la mundialización y nueva ciudadanía». Revista Estudios Socio-Jurídicos 11, n. 1: 11-38.

Organizaciones de Derechos Humanos de Guatemala. 2013. «Represión y criminalización de la protesta social en Guatemala», $149^{\circ}$ período ordinario de sesiones, Audiencia Temática, Washington, 28 de octubre. Consultado 20 enero 2020. https://www.academia.edu/39260541/REPRESI\%C3\%93N_Y CRIMINALIZACI\%C3\%93N_DE_LA_PROTESTA_SOCIAL_EN_GUATEMALA

Ospina, Pablo y Rickard Lalander. 2012. "Razones de un distanciamiento político: el Movimiento Indígena ecuatoriano y la Revolución Ciudadana». Revista del Observatorio Social de América Latina 32: 117-134.

Pearce, Jenny. 2010. «Perverse state formation and securitized democracy in Latin America». Democratization 17: 286-306.

Pearce, Jenny. 2017. «The Demonic Genius of Politics? Social Action and the Decoupling of Politics from Violence». International Journal of Conflict and Violence 11: 1-11.

Procuraduría de los Derechos Humanos (PDH) y Oficina del Alto Comisionado de Naciones Unidas para los Derechos Humanos (OACNUDH). 2018. Situación de las personas defensoras de derechos humanos en Guatemala: Entre el compromiso y la adversidad. Guatemala: PDH y OACNUDH. Consultado el 28 de noviembre 2018. https://www.oacnudh.org.gt/images/CONTENIDOS/ ARTICULOS/PUBLICACIONES/Informe_personas_defensoras.pdf

Pulido, Alejandro. 2012. «Militarización». En Diccionario crítico de empresas transnacionales. Editado por Juan Hernández Zubizarreta, et.al. 146-150. Bilbao: Hegoa y OMAL.

Rawls, John. 2004. El liberalismo político. Barcelona: Crítica. 
Redacción La Hora. 2013. «Alberto Rotondo, ejecutivo de minera dio orden para matar». La Hora, Guatemala, 9 de mayo de 2013. Consultado 20 noviembre 2019. https://lahora.gt/hemeroteca-lh/alberto-rotondo-ejecutivo-de-mineradio-orden-para-matar/

Sánchez, Armando. 2017. "Territorio, extractivismo y (des)ciudadanía en América Latina». El Cotidiano 201: 17-26.

Santos, Boaventura de Sousa. 2010. Para descolonizar Occidente. Más allá del pensamiento abisal. Buenos Aires: CLACSO y Prometeo Libros.

Santos, Boaventura de Sousa. 2005. «El uso contra-hegemónico del Derecho en la lucha por una globalización desde abajo». Anales de la Cátedra Francisco Suárez 39: 363-420.

Sepúlveda, Juan Ginés. 1941. Tratado sobre las Justas Causas de la Guerra contra los Indios. México, D.F.: Fondo de Cultura Económica.

Schmitt, Carl. 2006. El concepto de lo político. Texto de 1932 con un Prólogo y Tres Corolarios. Madrid: Alianza.

Schmitt, Carl. 2005. Teoría del Partisano. Acotación al concepto de lo político. Buenos Aires: Struhart \& Cía.

Solano, Luis. 2015. Estado de Sitio. Resistencia pacífica a Tahoe Resources y la militarización en Guatemala. Guatemala: Plataforma Internacional contra la Impunidad.

Svampa, Maristella. 2006. "Movimientos sociales y nuevo escenario regional: las inflexiones del paradigma neoliberal en América Latina». Sociohistórica 19-20: 141-155.

Svampa, Maristella. 2012. "Consenso de los commodities, giro ecoterritorial y pensamiento crítico en América Latina». Revista Observatorio Social de América Latina 32: 15-38.

Sutherland, Edwin. 1983. White Collar Crime. USA: Yale University Press.

Teitelbaum, Alejandro. 2010. «¿Dialogar con Ruggie? Cambiar para que todo siga igual... Una valoración de los informes 2009 y 2010 de John Ruggie». La Alianza Global Jus Semper, Breviario Temático LISDINYS. Septiembre: 1-10.

Teitelbaum, Alejandro. 2011. «Observaciones al informe final del Relator Especial John Ruggie sobre los derechos humanos, las empresas transnacionales y otras empresas». La Alianza Global Jus Semper, Breviario Temático LISDINYS. Mayo: 1-10.

Unidad de protección a defensoras y defensores de derechos humanos (UDEFEGUA). 2017. "Informe sobre situación de Defensoras/es de Derechos Humanos, Enero-diciembre 2017». Consultado 9 noviembre 2018. http://udefegua.org/wp-content/uploads/2018/07/Informe-2017. FINAL_.5.compressed.pdf?fbclid=IwAR2eM2XDfLSN5FSMc-4Htayy5UqaBos3_ D9PX0j7ch_eWi-t3P_brWz5Zd8

Vitoria, Francisco de. 1946. Relecciones sobre los Indios y el Derecho de Guerra, (1538-1539), Madrid: Espasa Calpe.

Weber, Max. 2016. La política como vocación. Valencia: NoBooks.

Zaffaroni, Eugenio R. 2009. Estructura básica del derecho penal. Buenos Aires: Ediar. 
Zaffaroni, Eugenio R. 2006. El enemigo en el Derecho Penal. Buenos Aires: Ediar.

Zibechi, Raúl. 2014. «El Estado de Excepción como paradigma político del extractivismo». Territorios en disputa. Despojo capitalista, luchas en defensa de los bienes comunes naturales y alternativas emancipatorias para América Latina compilado por Claudia Composto y Mirna Lorena Navarro, 33- 75. México DF: Bajo Tierra Ediciones.

Zizek, Slavoj 1997. "Multiculturalism, or the Cultural Logic of Multinational Capitalism». New Left Review 225: 28-51. 


\section{Copyright}

Deusto Journal of Human Rights / Revista Deusto de Derechos Humanos is an Open Access journal; which means that it is free for full and immediate access, reading, search, download, distribution, and reuse in any medium only for non-commercial purposes and in accordance with any applicable copyright legislation, without prior permission from the copyright holder (University of Deusto) or the author; provided the original work and publication source are properly cited (Issue number, year, pages and DOI if applicable) and any changes to the original are clearly indicated. Any other use of its content in any medium or format, now known or developed in the future, requires prior written permission of the copyright holder.

\section{Derechos de autoría}

Deusto Journal of Human Rights / Revista Deusto de Derechos Humanos es una revista de Acceso Abierto; lo que significa que es de libre acceso en su integridad inmediatamente después de la publicación de cada número. Se permite su lectura, la búsqueda, descarga, distribución y reutilización en cualquier tipo de soporte sólo para fines no comerciales y según lo previsto por la ley; sin la previa autorización de la Editorial (Universidad de Deusto) o la persona autora, siempre que la obra original sea debidamente citada (número, año, páginas y DOI si procede) y cualquier cambio en el original esté claramente indicado. Cualquier otro uso de su contenido en cualquier medio o formato, ahora conocido o desarrollado en el futuro, requiere el permiso previo por escrito de la persona titular de los derechos de autoría. 